\title{
LA ORTODOXIA DE UNA HETERODOXA: TERESA DE CARTAGENA Y LA BIBLIA*
}

\author{
POR \\ JUAN-CARLOS CONDE ${ }^{1}$ \\ Magdalen College, Oxford
}

\begin{abstract}
RESUMEN
Examina este trabajo la presencia y uso de textos bíblicos en las dos obras de Teresa de Cartagena, autora castellana del siglo $\mathrm{XV}$, Arboleda de los enfermos y Admiración Operum Dei, e inscribe estos usos literarios del texto bíblico en el contexto de los círculos y las corrientes de renovación espiritual, especialmente femenina, desarrollados en la península ibérica entre fines del siglo XV y comienzos del XVI, análisis que revela la afinidad de la mencionada autora con tales corrientes y círculos.

PALABRAS CLAVE: Teresa de Cartagena; Arboleda de los enfermos; Admiración Operum Dei; Salmos; Evangelios; espiritualidad; Castilla; Edad Media.

\section{THE HETERODOX PRACTICES OF AN ORTHODOX AUTHOR: TERESA DE CARTAGENA AND THE BIBLE}

\begin{abstract}
This article examines the presence and use of biblical texts in the two works written by the 15th-century Castilian writer Teresa de Cartagena, Arboleda de los enfermos and Admiración Operum Dei. It also explores this in the wide context of the circles and currents of spiritual renovation that were active in late medieval and early modern Spain, especially those with a prominent female presence, and determines the affinities of the said author with such circles and currents.
\end{abstract}

KEY WORDS: Teresa de Cartagena; Arboleda de los enfermos; Admiración Operum Dei; Psalms; Gospels; spirituality; Castile; Middle Ages.

Cómo CitAR este ARTículo / CitATION: Conde, Juan-Carlos. 2020. «La ortodoxia de una heterodoxa: Teresa de Cartagena y la Biblia». Hispania Sacra LXXII, 145: 115-123. https://doi.org/10.3989/hs.2020.009

\author{
Recibido/Received 21-02-2019 \\ Aceptado/Accepted 12-11-2019
}

\section{ACCESO}

En parte por ser el espíritu o lema bajo el que se convocó a los participantes en este número monográfico ( $y$ antes, a otros, a un seminario en la siempre sabia Salamanca), en parte por su constante combinación sutil en la obra y en las figuras de los más preclaros miembros de la familia Santa María-Cartagena, desde el patriarca el Obispo de Burgos $-\mathrm{y}$

* Este artículo se publica en colaboración con el proyecto de investigación Alfonso de Cartagena. Obras Completas FFI 201455902-P y FFI 2017-84858-P (Ministerio de Economía, Industria y Competitividad - Ministerio de Ciencia, Innovación y Universidades. Gobierno de España).

1 juan-carlos.conde@magd.ox.ac.uk /

ORCID iD: https://orcid.org/0000-0002-3877-5122 otrora Rabino Mayor de la misma- Pablo de Santa María, a su hijo y sucesor en la cátedra episcopal -y grandísima figura política, diplomática e intelectual de la Europa de su tiempo-, Alonso de Cartagena; sin olvidar a la nieta del uno y sobrina del otro, la monja Teresa de Cartagena - primera mujer escritora de fuste y peso en las letras peninsulares-, traigo ese par de opuestos, ortodoxia y heterodoxia, al título de estas paginillas, paginillas encaminadas a la indagación de la presencia del texto escriturístico en las obras del último miembro dicho de tan ilustre estirpe burgalesa. Dos polos de oscilante distancia, marcada por una tensión tan inevitable como resbaladiza.

Esa tensión entre ortodoxia y heterodoxia que parece presidir la ubicación de las grandes personalidades de esta familia en el amplio contexto de la cultura y las letras castellanas del Cuatrocientos parece agravarse en el caso de 
Teresa de Cartagena, por razón de la que añade a su figura y a su proyección social y cultural el hecho de su condición de mujer, y de mujer escritora y de letras, combinación que la sociedad de su tiempo no estaba preparada, o dispuesta, a aceptar sin ciertos reparos o muy cierto rechazo. ${ }^{2}$ En el caso de nuestras páginas de hoy, pasearemos por los senderos de la Teresa ortodoxa, y la heterodoxia figurará más bien como el implícito entorno pragmático en que esta escritora llevó a cabo su tarea de pensadora y escritora.

No es, todavía, la figura de Teresa de Cartagena tan conocida en detalle como debiera incluso dentro de los círculos de aquellos familiares, por oficio o devoción, con las letras y la historia de la Castilla de la tardía Edad Media, por lo que no será tiempo perdido - espero- esbozar aquí mínimamente su perfil biográfico y dar alguna noticia de sus obras. ${ }^{3}$ Nacería hacia 1424-1430 en Burgos, donde se hallaba radicada desde hacía decenios su familia, la muy influyente familia judeoconversa de los Santa María-Cartagena, y donde vivían su padre, Pedro de Cartagena, tercer hijo varón de Pablo de Santa María, y la familia que creó con su mujer, María de Sarabia. ${ }^{4}$ La joven Teresa hubo de recibir una educación esmerada (que llegó a incluir, según ella misma dice en una de sus obras, la asistencia a actividades docentes en la Universidad de Salamanca, cosa harto insólita para una mujer en aquellos tiempos), y desarrollaría intereses literarios y cultos; tras un malogrado intento de matrimonio optó por abrazar una existencia en religión, y profesó en el convento de Santa Clara de Burgos en una fecha en torno a 1440 , no posterior a 1445 . No permaneció, parece ser, en ese cenobio demasiado tiempo. Su presencia en él está documentada hasta noviembre de 1452, no más tarde, y en 1449, a petición de su tío Alonso, se le había concedido dispensa papal para cambiar de orden religiosa y trasladarse a otro convento, así como para ocupar dignidades, incluida la abacial, en aquel al que se la autorizaba a transferirse. Parece ser que este fue el de las Huelgas Reales, convento cisterciense que fue el predilecto de las mujeres no matrimoniadas de la realeza y la nobleza castellanas. A día de hoy no hay constancia documental de que ese traslado se verificara, más allá de la solicitud de dispensa papal mencionada (y quién sabe qué queda en los afligidos archivos de las Huelgas Reales, a los que lamentablemente no se me ha permitido acceder); pero es lo habitual entre los estudiosos de la vida de nuestra autora pensar que el traslado se verificó en torno a fines de 1452-comienzos de 1453, quizá algo más tarde. Y la principal razón para creerlo así es que Teresa de Cartagena resultó

2 Similar matriz de tensión paradójica entre opuestos a la aludida se refleja, también ya desde el título, en uno de los trabajos que he dedicado a Teresa de Cartagena (Conde 2015). Me he ocupado recientemente del análisis de la conflictiva intersección del ejercicio de las letras por parte de Teresa de Cartagena con la ideología hegemónica de la sociedad de su tiempo en Conde (en prensa).

3 La compilación de informaciones biográficas sobre Teresa de Cartagena más completa publicada hasta el día de hoy es SeidenspinnerNúñez y Kim (2004); la aparición de la edición de las obras de Teresa de Cartagena que ultimo en estos días aportará novedades significativas para la biografía de la autora (Cartagena en prensa). El resumen biográfico que aquí facilito es un mínimo extracto de las informaciones más relevantes que en su estudio preliminar se contendrán.

4 Para el estudio y conocimiento de la familia Santa MaríaCartagena siguen siendo esenciales esos dos grandes estudios que son Serrano (1942) y Cantera Burgos (1952). aquejada de sordera en torno a 1453-1459, y que verosímilmente el traslado y la dispensa para ocupar dignidades abaciales no se le hubiera concedido, como así fue, en 1449 de haber sido ya sorda entonces. En su nueva y muy distinguida casa del Cister desarrollaría Teresa de Cartagena su obra literaria, ya bastantes años después. La primera de ellas, Arboleda de los enfermos, escrita en torno a 1469-1475, tiene como tema principal su sordera. En cuanto a segunda de ellas, Admiración operum Dei, el hecho de que esta obra fuera escrita en respuesta a las reacciones inamistosas que suscitó la difusión de Arboleda, hace razonable pensar que fuera escrita no mucho después de la fecha de redacción de esa obra, acaso en torno a 1470-76; en ningún caso después del 31 de diciembre de 1481, fecha que consta en el explicit -autorial, no de copista- que aparece en una de las obras copiadas, y por el mismo copista que copia las de Teresa de Cartagena, en el fol. 79r del manuscrito que nos ha transmitido estas, el h.Ill.24 de la Biblioteca del Real Monasterio de El Escorial. Carecemos de información acerca de la fecha de su muerte y del lugar de su sepultura: Teresa de Cartagena se nos difumina entre las nieblas de la historia sin dejar rastro en sus últimos años de su vida.

Debía de contar Teresa de Cartagena con unos 40-45 años cuando escribió Arboleda de los enfermos en 1469-1475, cuando ya llevaría cerca, si no más, de veinte años en el convento de las Huelgas y cerca de quince, si no alguno más, padeciendo la sordera que es tema principal de esa obra. Pues, en efecto, Arboleda de los enfermos es un tratado - con ese tecnicismo genérico lo califica su autora $-{ }^{5}$ que encierra una justificación teológica de la enfermedad, del sentido y propósito de su existencia, que, a su vez, puede verse como obra consolatoria para todos aquellos que padecen enfermedad. ${ }^{6}$ Si desplazamos la mirada al objeto de nuestro interés hoy, pronto advertimos que el texto bíblico como fuente e inspiración de Arboleda aparece explícitamente nombrado en el texto desde muy pronto, ya en su prólogo, y en intersección con la enfermedad que da origen a la obra. Este pasaje del prólogo es una declaración fundamental del carácter de la obra, de la

5 Este término determina la adscripción genérica de la obra, y corresponde a su significado originario y básico —en lengua latina (tractatus) y española igualmente- pero en ningún modo exclusivo, de 'texto en que se abordan analítica y filosóficamente hechos y conceptos no ficcionales'. Vid. el clásico trabajo de Keith Whinnom (1982), especialmente la página 213. Si bien dedicado al uso de tratado como título de obras de ficción y los problemas que plantea (pese a que su uso -el de tractatus, esto es- está documentado en latín desde el siglo XII), el artículo de Whinnom ofrece útiles reflexiones para contextualizar la presencia y el sentido del término tractado en la rúbrica inicial de esta obra. La amplia virtualidad denotativa del término tratado queda cartografiada muy ilustrativamente en Infantes $(2001,733)$, con mención a Arboleda de los enfermos.

6 Inmejorablemente lo compendia la rúbrica que introduce el texto en el único manuscrito de la obra, el ya mencionado escurialense h.III.24: "Este tractado se llama Arboleda de los enfermos, el qual conpuso Teresa de Cartajena seyendo apasyonada de graves dolencias, especialmente aviendo el sentido del oýr perdido del todo, e fizo aquesta obra a loor de Dios e espiritual consolaçión suya e de todos aquellos que enfermedades padesçen, porque despedidos de la salud corporal levante[n] su deseo en Dios, que es verdadera salut» (fol. $1 \mathrm{r}$ / p. 37). Cito por mi edición en prensa (Cartagena en prensa), pero ofreciendo indicación del folio del manuscrito en que se ubica el pasaje y del número de la página en que se halla en la benemérita edición de Lewis J. Hutton (Cartagena 1967), única hoy accesible -y a duras penas- de las obras de Teresa de Cartagena. 
situación en que se halla la autora cuando emprende su tarea y de su principal fuente de inspiración - si todavía puede utilizarse un término que tanto huele a naftalina-:

Porque mi pasyón es de tal calidat e tan porfiosa que tan poco me dexa oýr los buenos consejos como los malos, conviene sean tales los consejos consoladores que syn dar bozes a mi sorda oreja me pued[a]n poner en la claustra de sus graçiosos e santos consejos, para lo qual es neçesario de recorrer a los libros, los quales de arboledas saludables tienen en sý maravillosos enxertos. E como la baxeza e grosería de mi mugeril yngenio a sobir más alto non me consienta, atreviéndome a la nobleza e santidat del muy virtuoso Rey e Profeta llamado Davit, comienço a buscar en su devotísymo cançionero que Salterio se llama algunas buenas consolaçiones, y fallé más de lo que buscaba: ca yo buscava consolaçiones y allé amonestaçiones; buscava consejos e fallélos syn dubda tantos y tales que sy por ellos guiarme quisyere poblaré mi soledat de arboleda graçiosa, so la sonbra de la qual pueda descansar mi persona, y reçiba mi espíritu ayre de salud (fol. 1v / p. 38).

Permítaseme aquí un salto atrás. Ya antes, ya en las primeras líneas del prólogo, consta en Arboleda la presencia directa del libro de los Salmos. El prólogo de la obra, dirigido a una "virtuosa señora» de ignota identidad, se abre con una metáfora alegorizante de naturaleza espaciadora en que la autora se presenta a sí misma como afectada por una "niebla de tristeza tenporal e humana» y por un "espeso torvellino de angustiosas pasyones» (fol. $1 \mathrm{r} / \mathrm{p}$. 37) -alusiones tan metafóricas como transparentes a la enfermedad que le aqueja-, afección que la llevó «a una ýnsula que se llama "Oprobrium hominum et abieçio plebis». Es una cita directa del latín del muy deprecatorio Salmo 21(22), 7-8: «Ego autem sum vermis, et non homo; / Opprobrium hominum, et abiecio plebis. / Omnes videntes me deriserunt me; / Locuti sunt labiis, et moverunt caput». La enfermedad como causa de aislamiento debido al rechazo físico que el enfermo causa a sus prójimos viene vehiculada y autorizada por una cita directa - en latín- del Salterio, cuya presencia en el texto se muestra urgente y perentoria. La marginación, el rechazo social, como precio que el enfermo paga, confinado en esa isla metafórica que resulta ser «estérile de plazeres tenporales e muy seca de glorias vanas» (fol. $1 \mathrm{r} / \mathrm{p}$. 38), vendrán aliviados por «arboledas de buenos consejos y espirituales consolaçiones» (fol. 1v / p. 38), arboledas de nuevo metafóricas que proveen de su título a la obra.

Volvamos al pasaje del prólogo de Arboleda antes citado, en el que la autora explícitamente declara su apego al Salterio de David. Cartagena, pues, nos dice que la Biblia, concretamente el Salterio, el libro de los Salmos, ${ }^{8}$ es la fuente a la que acude en busca de consejo y consuelo, y que encontró ahí, y con creces, uno y otro; encontró, de hecho, el punto de partida -el «fundamento», según sus propias palabras (fol. 2v / p. 40) - para su tratado, que no es otro que la segunda parte de Sal 31(32),9: «In camo et freno maxillas eorum constrinje,

7 En lo sucesivo daré entre paréntesis, siempre que sea menester, la numeración en la Biblia hebrea del salmo citado.

8 Históricamente su autoría se atribuye, al menos parcialmente, a David, rey de Israel. La índole poética por naturaleza del libro de los Salmos y la reputación del rey David como excelente músico y poeta está detrás de su definición por parte de Teresa de Cartagena como «devotísymo cançionero». Sobre la autoría de David, vid. Rendtorff (2005). qui non aproxima[n]t a[d] te». ${ }^{9}$ Esta cita bíblica está copiada en el manuscrito en tinta roja y como párrafo independiente. Tal disposición gráfica en la página coincide con la relevancia que la autora dice dar a ese pasaje bíblico, tomándolo «por fundamento» de su obra: efectivamente, más adelante lo glosará y amplificará detalladamente, de manera no de todo disimilar a como el thema de un sermón es glosado y amplificado a lo largo del mismo.

\section{CARTOGRAFÍA}

Ya desde esta instancia inicial el texto bíblico en general, y los Salmos en particular, se revelan como la principal fuente de autoridad a la que recurre la autora de Arboleda, tanto en esta obra como en Admiración. Las citas y referencias bíblicas identificadas en las obras de Teresa de Cartagena andan en torno a las 123, 78 en Arboleda y 45 en Admiración, texto sustancialmente más corto -72 páginas frente a 30 en la edición de Hutton- ${ }^{10}$ De esas presencias bíblicas en el texto de las obras de Teresa de Cartagena, 38 corresponden al libro de los Salmos, 21 de ellas presentes en Arboleda, las restantes en Admiración. Las cifras nudas dan una idea patente de la impronta bíblica presente en las obras de Teresa de Cartagena, y de la prominencia especial que en ellas ostenta el libro de los salmos del rey David. ${ }^{11}$

Como ya se ha dicho, y como muestran diáfanamente las tablas de la tesis de Pearson ya citadas, estas huellas bíblicas en las obras de nuestra autora se presentan en algunos casos como citas directas (que el editor moderno no vacila en editar entrecomilladas) introducidas como tales y en algunos casos incorporando alusión más o menos vaga a su autoría o procedencia; en otros casos son más bien ecos, alusiones, acomodaciones en la propia obra de huellas figurales, fraseológicas o léxicas de procedencia bíblica. Me limitaré a dar aquí ejemplos de lo primero, como las citas ya citadas, y reproducidas aquí de nuevo, más las que siguen: ${ }^{12}$

9 El Salmo completo, según la Vulgata, es «Nolite fieri sicut equus et mulus, / Quibus non est intellectus. / In camo et freno maxillas eorum constringe, / Qui non approximant ad te» (No seas sin entendimiento, como el caballo y el mulo: / con la brida y el freno hay que sujetar su ímpetu; / de lo contrario, no se acercan a ti).

10 Para su identificación son valiosísimas las aportaciones efectuadas en las notas con que Hutton acompañó su edición de las obras de Teresa de Cartagena (Cartagena 1967, 145-153) y los cuatro apéndices que Hilary Pearson añadió a su tesis, tabulando citas directas y referencias indirectas al texto bíblico tanto en Arboleda como en Admiración (Pearson 2010, 288-296). Me tomo la libertad de complementar y corregir la información proporcionada en esas fuentes, como se verá ocasionalmente en estas páginas y más exhaustivamente en las de mi futura edición. Este es un momento tan bueno como cualquier otro para declarar que en este trabajo no me ocupo de las fuentes no bíblicas -eminentemente patrísticas, y también Boecio- utilizadas por Teresa de Cartagena en sus obras. El interesado hallará información relevante en las citadas notas de Hutton a su edición y en los apéndices de Pearson a su tesis (Pearson 2010, 297-299) en que lista las fuentes no bíblicas expresamente presentes en la obra de nuestra autora. Esa lista le permitirá ver la relevancia secundaria que las fuentes no bíblicas tienen en sus obras, pese a que su presencia no pueda calificarse de menor.

11 Sorprende por ello sobremanera que no haya mención alguna a ellas en los valiosos dos tomos dedicados al período medieval de la obra colectiva La Biblia en la Literatura Española (Toro Pascua 2008a y 2008b).

12 Van seguidas de referencia al libro bíblico al que pertenecen; a la obra de Teresa de Cartagena en que se hallan, y a su ubicación en el manuscrito y en la edición de Hutton; en nota al pie se da el texto de 
- La niebla de tristeza tenporal e humana cubrió los términos de mi bevir, e con un espeso torvellino de angustiosas pasyones me llevó a una ýnsula que se llama «Oprobrium hominum et abieçio plebis» (Sal 21(22), 7-8; Arboleda, fol. $1 \mathrm{r} / \mathrm{p} .37){ }^{13}$

- Do fin al prólogo y comienço a la pequeña y defetuosa obra, por fundamento de la qual me plaze tomar las palabras siguientes: «In camo et freno maxillas eorum constrinje, qui non aproxima[n]t a[d] te» (Sal 31(32), 9; Arboleda, fol. 2v / p. 40). ${ }^{14}$

- E aun me pareçe, sy bien lo entiendo, que asý lo amonesta el Profecta donde dize: «Pregunta al tu padre e anu[n]çiará a ti, e los tus mayores dirán a ti» (Dt 32, 7; Arboleda, fol. 3v-4r / p. 41)..$^{15}$

- E con el silençio ya dicho, ynclinando la oreja del mi entendimiento (pues la del cuerpo mal me ayuda), parésçeme que espiritualmente oý resonar aquestas palabras: "oye, fija, e acata e inclina tu oreja, olvida el pueblo tuyo y la casa de tu padre» (Sal 44 (45), 11; Arboleda, fol. $5 \mathrm{v} /$ p. 44). ${ }^{16}$

- Plega al Señor soberano que asý velantes en obras virtuosas nos halle que se nos pueda atribuýr e podamos gozar de aquella palabra evangélica que dize: «Bien aventurado aquel siervo que quando viniere el señor suyo le hallare vigilante» (Lc 12, 37; Arboleda, fol. 10r / p. 50). ${ }^{17}$

- Este mesmo Profecta ${ }^{18}$ dize en otro logar: "Señor, muéstranos la tu haz y seremos salvos» (Sal 79 (80), 4; Arboleda, fol. $10 \mathrm{v} /$ p. 51). ${ }^{19}$

- De ser la oraçión propia aldava para llamar a la puerta de la misericordia de Dios su mesma palabra lo declara, onde dize: "Qualquier cosa que orando pidierdes, creed que lo reçibirés» (Mt 21, 22; Arboleda, fol. 14r / p. 56). ${ }^{20}$

- Más abiertamente lo declara este mesmo Profecta, donde dize: «Llamará a Mí e Yo lo exaudiré; con e[s]so en la tribulaçión librar le he, e glorif[ic]ar le he» (Sal 90 (91), 15; Arboleda, fol. 17v / p. 61). ${ }^{21}$

- E aun no me consiente mi devoçión poner e[n] olvid[o], antes me manda traer a la memoria, una palabra que

la Vulgata del pasaje bíblico en cuestión. Como muestran las dos primeras citas, Teresa de Cartagena utilizó el texto de la Biblia latina; más adelante examinaremos algunos datos textuales más que confirman el manejo del texto latino por parte de nuestra autora.

13 «Ego autem sum vermis, et non homo; / Opprobrium hominum, et abiecio plebis. / Omnes videntes me deriserunt me; / Locuti sunt labiis, et moverunt caput».

14 «Nolite fieri sicut equus et mulus, / Quibus non est intellectus. / In camo et freno maxillas eorum constringe, / Qui non approximant ad te».

15 «Interroga patrem tuum, / Et annuntiabit tibi: / Maiores tuos, et dicent tibi».

16 «Audi, filia, et vide, et inclina aurem tuam; / Et obliviscere populum tuum, et domum patris tui».

17 «Beati servi illi quos, cum venerit dominus, invenerit vigilantes».

18 La referencia demostrativa apunta a la discusión de Sal 31 (32), 19 que precede inmediatamente a este pasaje.

19 "Deus, converte nos, / Et ostende faciem tuam, et salvi erimus».

20 «Et omnia quaecumque petieritis in oratione credentes, accipietis».

21 «Clamabit ad me, et ego exaudiam eum; / Cum ipso sum in tribulatione; / Eripiam eum, et glorificabo eum». La presencia del infrecuente exaudiré en el texto de Arboleda delata la presencia del texto latino como subyacente al pasaje. en la estoria deste Santo Apóstol se escrive, donde dize: «la virtut en la enfermedat es acabada [e] perfecta» (II Cor 12, 9; Arboleda, fol. 18v / p. 62). ${ }^{22}$

- Por ellos creo se puede dezir aquello que el Profeta dize en el Salmo: "Yrán de virtud en virtut y verán a Dios de los dioses en Syón» (Sal 83 (84), 8; Arboleda, fol. $26 \mathrm{v} /$ p. 72$)^{23}$

- Onde dize el salmista: «El te[m]or del Señor es y permanesçe en todos los syglos»; y en otro lugar dize: "Comien[ç]o de la sabiduría es el temor de Dios» (Sal 18 (19), 10 y Sal 110 (111), 10 respectivamente; Arboleda, fol. 33r / p. 81)..$^{24}$

- E aun así lo [de]clara e confirma la conclusyón de los loores deste muy famoso Maestro y Enxenplo de las Paçiençias onde dize: «En todas estas cosas non pecó Job en los sus labrios, ni alguna palabra vana contra Dios á fablado, etc. (Job 1, 22; Arboleda, fol. 44v / pp. 99-100). ${ }^{25}$

- De ser la henbra ayudadora del varón leémoslo en el Génesy, que después que Dios ovo formado el onbre del limo de la tierra e ovo ysp[i]rado en él espíritu de vida dixo: «No es bueno que sea el onbre solo; hagámosle adjutorio semejante a él» (Gén 2, 7 -cita indirecta-y Gén 2, 18; Admiración, fols. 53v-54r / p. 118). ${ }^{26}$

- E dize el Apóstol: «Donde abundó el delito ende sobreabundó graçia, etc.» Rom 5, 20; Admiración, fol. $57 \mathrm{r} / \mathrm{p} .124) .{ }^{27}$

- E aun creo por çierto que esta es la ad[miraçión] que el profeta nos enseña en el salmo donde dize: «iSeñor, Señor nuestro, quán maravilloso es el tu nonbre en toda la tierra!» (Sal 8, 2; Admiración, fol. 57v / p. 125$){ }^{28}$

- E dize adelante: «Él mesmo la crió por espíritu, ca la divide e aparta y dinumera e derrama sobre todas las obras suyas e sobre toda carne, segund el don suyo, e la da a los amadores de sý o a los que le aman, etc.» (Eclo 1, 9-10; Admiración, fol. 58v / p. 127). ${ }^{29}$

- Él ynclinó su oreja a mí, que çercada [de] grandes angustias e puesta en el muy hondo piálago de males ynrepara[b]les le llamava con el Profeta diziendo: "Sálvame, Señor, ca entra el agua hasta el ánima mía» (Sal 68 (69), 2; Admiración, fol. 61r / p. 131). ${ }^{30}$

\footnotetext{
22 «Sufficit tibi gratia mea: nam virtus in infirmitate perficitur».

23 «lbunt de virtute in virtutem, / Videbitur Deus deorum in Sion».

24 "Timor Domini sanctus, permanens in saeculum saeculi»; «Initium sapientiae timor Domini».

25 «In omnibus his non peccavit lob labiis suis, neque stultum quid contra Deum locutus est».

26 «Formavit igitur Dominus Deus hominem de limo terrae, et inspiravit in faciem eius spiraculum vitae»; "Dixit quoque Dominus Deus: Non est bonum esse hominem solum: faciamus ei adiutorium simile sibi».

27 "Ubi autem abundavit delictum, superabundavit gratia», y nótese la impronta del texto bíblico subyacente en el léxico del pasaje.

28 «Domine, Dominus noster, / Quam admirabile est nomen tuum in universa terra!».

29 «Ipse creavit illam in Spiritu Sancto, / Et vidit, et dinumeravit, et mensus est. / Et effudit illam super omnia opera sua, / Et super omnem carnem, secundum datum suum, / Et praebuit illam diligentibus se». Nótese la errónea puntuación con que Hutton configuró el pasaje (Cartagena 1967, 127), así como la innegable huella del texto subyacente en el léxico del mismo.

30 «Salvum me fac, Deus, / Quoniam intraverunt aquae usque ad animam meam».
} 
- Onde el Profeta, mostrando que en estas dos cosas consyste el temor de Dios, dize: «Venid, hijos; oýd a mí. El temor del Señor enseñará a vos» (Sal 33 (34), 12; Admiración, fol. 63 r / p. 136). ${ }^{31}$

- E dirán en aquél día: «Confesad al Señor e ynvocad al su santo Nonbre, quod est et beneditum in secula seculorum» Amen (Sal 144 (145), 21; Admiración, fol. $66 r /$ p. 141)..$^{32}$

Esta breve y sumaria muestra de la presencia de pasajes bíblicos en la obra, expresamente citados como tales, muestra no solo la intensa presencia de las Escrituras en las obras de Cartagena, sino también permite advertir algunas de las estrategias discursivas mediante las que las citas bíblicas se entretejen con el texto, frecuentemente enmarcándolas con una referencia autorial o de procedencia que ampara su autoridad, calificable como estática y hierática en su poder autorizante. Pero no es esto lo que me parece más interesante de la impronta bíblica que ahorma las obras de Teresa de Cartagena, sino otros pasajes donde el texto, lejos de ser letra portadora de autoridad autoevidente, es texto que requiere de operaciones exegéticas ante las que nuestra autora no se arredra en absoluto. Ya que los límites razonables de un artículo no permiten revisar todas las instancias de esto presentes en las obras de nuestra autora, revisemos en lo que sigue uno de esos pasajes de las obras de Teresa de Cartagena, en concreto en Arboleda de los enfermos. ${ }^{33}$

\section{APLICACIÓN}

Ocupémonos de esto, por qué no, retornando a un punto de Arboleda que dejamos en suspenso páginas atrás, aquel en que la autora sitúa precisamente un versículo de los Salmos como "fundamento» - es la palabra que emplea, como ya se dijo- de su obra. Efectivamente, el ya mencionado Sal 31 (32), 9, "Nolite fieri sicut equus et mulus, / Quibus non est intellectus. / In camo et freno maxillas eorum constringe, / Qui non approximant ad te», en concreto sus dos últimos versos, abren paso a la consideración teológica y consolatoria de la enfermedad como bien. Será a partir del fol. 8 r cuando nuestra autora nos muestre "cómo e quánto haze a mi propósyto esta autoridat», y la palabra, por supuesto, no es casual. Cabestro y freno, nos dice, son propios de animales, «animales brutos que carecen de razón, porque con estos artifiçiales atamientos son traýdos

31 «Venite, filii, audite me; / Timorem Domini docebo vos». Adviértase la discrepancia entre el texto de la Vulgata y el de Admiración, consecuencia sea de un mal entendimiento de un acusativo por un nominativo, sea de una variación textual en el texto bíblico subyacente utilizado por Teresa de Cartagena.

32 "Laudationem Domini loquetur os meum; / Et benedicat omnis caro nomini sancto eius in saeculum, et in saeculum saeculi».

33 Otros episodios merecedores de análisis en términos de su condición de comentario exegético de pasajes bíblicos apto para canalizar autorizadamente el mensaje de la autora son, en Arboleda, el del salmo "Audi, filia» (Sal 44 (45), 11; fols. 5v-8r, pp. 44-47), el de la parábola de los invitados descorteses contenida en Lc 14, 15-24 (fols. 13r-14r, pp. 54-56), el de la parábola de los cinco talentos (Mt 25, 14-30), que se erige en marco estructural para una parte sustancial de la obra (fols. 24r-41v, pp. 69-94); o, en Admiración, la historia de Judit y Holofernes, narrada en el libro veterotestamentario de Judit y utilizada como historia ejemplar particularmente adecuada para los fines que la autora busca en la segunda de sus obras (fols. 54v-55v, pp. 119-121). casy por fuerça adonde les cunple e al serviçio de su dueño conviene, asý que por el cabestro son guiados e por el freno costreñidos» (8v). Esta imagen animal que el salmo citado aplica a los seres humanos es significativa en los términos que la autora inmediatamente nos explica, desvelando el sentido alegórico del pasaje bíblico:

E ansý como en la boca e çerviz de los ya dichos animales es puesto cabestro e freno por las dichas razones, bien ansý paresçe por otras dos semejantes causas ser dado a todo animal razonable cabestro $y$ freno. El cabestro es la razón y el freno es la tenprança y discrición, ca la razón nos guía e deve guiar a todo lo que es bueno y conplidero, no sólo a nuestro bien tenporal, mas a lo espiritual e pertenesciente al serviçio de Nuestro Señor; e la tenplança y dyscriçión nos costriñe a refrenar los apetitos desordenados de nuestra humana flaqueza (fols. $8 \mathrm{r}-8 \mathrm{v} / \mathrm{pp}$. 47-48).

Sigue aquí nuestra autora pasos no divergentes de los pautados por la Glossa Ordinaria, donde se lee, aplicado a "Quibus non est intellectus» que «nulla culpa est in brutis animalibus quia non habent intellectum per quam possint refrenare appetitum sensitivum; sed in hominibus rationem habentibus est hoc valde culpabile, quia per rationem possent appetitum sensitivum refrenare» (Biblia c1487 II: fol. Pv $\vee-a$ ). Los irracionales necesitan de esos dispositivos coercitivos, mientras que los seres racionales, dotados de razón y entendimiento (y templanza y discreción, añade la nuestra), no requieren de ellos, siempre que opten por comportarse conforme a lo que su entendimiento les permite.

No es ese, con todo, el caso general. «Todo animal razonable tiene en su poder y querer estos dos buenos aparejos para se regir, pero no todos usan ygualmente dellos, segund se puede juzgar por los actos de cada uno", nos dice Teresa de Cartagena: «avemos visto y vehemos a unos rotamente pecar e a otros vitoriosa e honestamente bivir, y a otros [de] mediana suerte, de guisa que ni muy disolut[o]s en lo uno ni muy perfectos en lo ál» (fol. $8 \mathrm{v}$ ambas citas). La razón de ello es clara:

En la humanidat no ay diferençia ninguna, que tan bien el mucho virtuoso como el mucho pecador, e tan bien el moderado como el disoluto, ygualmente la ynclinación humanal los conbida a pecar: de qualquier pecado que el más pecador del mundo comete puede ser tentado y aun reziamente conbatido el más virtuoso e onesto que en esta vida hallar se puede» (fol. 8 v / p. 48).

"Humanal cosa es pecar», dijo Juan Ruiz cerca de siglo y medio antes, precisamente embarcado en la exégesis sermocinal de Sal 31 (32), 8, el versículo precedente al que Cartagena toma como su "fundamento». Nuestra autora coincide, pero toma otro cauce menos indulgente:

Donde se sygue que el onbre que no sabe o no quiere saber aprovechar ni regir por el cabestro y freno dicho es animal, pero no razonable, pues no usa de aqueste nonbre, ca el propio exerçiçio de la razón es el que nos amonesta e costriñe a desear el bien e esquivar el mal, pues quien dexa el bien y sigue el mal paresçe qu[e] desanpara a la razón o la razón desanpara a él.

El corolario lleva a una conclusión irrefragable: «sugund esto, bien es, y más de bien, serle añadido otro freno, asý como animal bruto» (ambas en fol. 9r / p. 48). Conclusión 
analógica que nuestra autora no se saca de la manga, sino que sigue al pensar así lo dicho en la mencionada Glossa Ordinaria, donde se lee, aplicado a «In camo et freno maxillas eorum constringe qui non approximant ad te»: "Eos qui nolunt obediri tibi, sicut equus indomitus penis et laboribus eos afflige, ita quod pena dante eis intellectum obediant tibi» (Biblia c1487 II: fol. Pv ooa). Como animal bruto, sicut equus indomitus, el pecador requiere de cabestro y freno. $Y$ esto es lo que Teresa de Cartagena expande a continuación, aplicándose el cuento y aplicándoselo a aquellos que, como ella, padecen de enfermedad:

Agora veréys cómo tiene su fin derechamente contra mí esta buena abtoridat sobredicha, "Yn camo et freno, etc."; e porque más claramente veaes ser mía e yo suya, pues me llama adonde quiere, diré lo que mi sinpleza me presenta para socorro de aquesta pobre y desnuda escritura. Digo e afirmo que por mi grand bien y manifiesto provecho el Señor soberano con cabestro y freno de dolençia e pasyones costriñó las mexillas de mis vanidades (fol. 9 r / pp. 48-49).

A vueltas con el habitual tópico de modestia, la autora presenta la enfermedad que la aflige como uno de esos cabestros y frenos con que los pecadores pueden verse forzados a mantenerse en el buen camino. Y lo explica, con el fundamento proporcionado por el verso del Salmo, con estrategias discursivas propias de la escritura exegética o, incluso, asimilables a las técnicas de las artes sermocinales. No cabe reproducir aquí en su integridad el pasaje en que nuestra autora desarrolla su expositio del sentido del citado Salmo (fols. 9r-13r), pero sí mostrar algunos pasajes que la presentan embarcada en la construcción de un discurso doctrinal exegético conforme a lo requerido por las convenciones del género en aquellos tiempos. Así se inicia:

Pues veamos cómo la dolençia se puede llamar cabestro y freno. Syn dubda me [cre]an los que no la conocen; a los que la conosçen la espirençia jelo fará conocer, que sus propios actos la fazen cobradora deste nonbre. La dolençia buena y durable es cabestro para abaxar la çerviz de sobervia e es freno para costreñir y evitar los deseos dañosos y enpeçibles al ánima. E aun en esta tenporal vida que a nuestros ojos pareçe avemos exenplo, ca veemos que un onbre enfermo no osa ni osará comer de todas las viandas, e aun de las menos dañosas no come quanto quiere. Pues ya paresce que en los actos corporales resiste y enfrena la dolençia, ved qué deve hacer en los espirituales; ca sy discriçión pone regla en las viandas por conservar la salut tenporal, mayor discreçión e de más durable provecho es en verdat poner regla en las obras por defensyón y guarda de la salut espiritual (fols. 9r-9v / p. 49).

La analogía que presenta la autora con la situación que experimenta el enfermo respecto de su alimentación (ampliable sin demasiado esfuerzo a otros aspectos de su vida sensitiva) aplicada a la que experimenta respecto de su vida espiritual es desarrollada con cuidado y calma, y su significado final o sentencia, alcanzado con evidencia manifiesta:

Sea verdat que a todos sería o es conplidero y no poco saludable guardar diecta en el dañoso manjar de los pecados, pero no es dubda que más abiertamente lo amonesta la razón a los enfermos que no a los sanos; ca asý como en las viandas corporales [a] todos es bien guardarse de lo dañoso, pues çierto es que en más estrecho y con mayor premia es costreñido de se guardar el enfermo que el sano, bien asý de los manjares dañosos al ánima que son los pecados con más premia y manifiesta neçesidat se deve abstener el enfermo que no el sano. ¡O, asaz clara está la sentencia! Lo primero, porque el doliente está asý preso que lo tenporal o corporal ni puede aprovechar a sý ni a los otros; pues estar ocçioso en lo espiritual, ¿̇ué demasyada negligençia os paresçe que sería? Lo segundo, y que más despierta la causa, es porqu'el enfermo ya paresçe tener el pie en el estribo para partir desta vida; aunque algunas vezes acaesçe que más aýna parte desta miserable vida el sano que no el enfermo, ca avemos visto y vehemos algunos bevir muchos años con grandes dolençias, e a otros que en su sanidad floresçen avemos visto por nuestros pecados partir desta vida de grande arrebato. Aquí miren los que de la salut corporal son bien guarneçidos, porque el sueño de aquesta suguridat no los apremie de tal guisa que la açelerada e forçosa partida los halle durmiendo. Mucho olvidé a mí mesma en esto que dixe: "miren los que de salud corporal son bien guarneçidos", c'aunque la seca salut me haze apartada deste número, el sueño de los pecados más adormida me tiene que a otro ninguno. Por ende quiero dezir que miren e miremos, asý enfermos como sanos, que no nos tome durmiendo esta partida que muerte se llama, mas plega al Señor soberano que asý velantes en obras virtuosas nos halle que se nos pueda atribuýr e podamos gozar de aquella palabra evangélica que dize: "Bien aventurado aquel siervo que quando viniere el señor suyo le hallare vigilante" (fol. 9v-10r / pp. 49-50).

La cita bíblica que cierra el largo desarrollo exegético («Beati servi illi quos, cum venerit dominus, invenerit vigilantes» Lc 12,37$)$ lo clausura remachando su mensaje de advertencia y caución con un refuerzo de autoridad. El desarrollo exegético se verifica con consistencia conceptual, con solidez dispositiva y hasta con efusión elocutiva e implicación emocional de la propia autora y emisora. No estamos lejos del tono y las formas de un sermón bien armado, o de un tratado espiritual capaz de sentar las bases de la futura escritura espiritual de los autores del XVI versados en esos temas. ${ }^{34}$

Y ello especialmente por el espacio señaladamente significativo que en esta escritura ocupa la consciente introspección subjetiva de la autora. En efecto, a partir de ese ejercicio de interpretación y exégesis bíblica, que explana y franquea el sentido profundo del pasaje de las escrituras que la autora elige, pasa a aplicarlo de manera preferente a su caso y experiencia personales. Así se expresa a continuación nuestra autora:

E dexando esto, porque va lexos de mi propósyto e no menos arredrado de mi menes[t]er, digo que por las cabsas ya dichas e por muchas más que dexo de dezir, se pueden e deven llamar las dolençias e pasiones corporales cabestro e freno. ¿Pues quánto con mayor razón e más propio exerciçio se puede dezir por esta mi pasyón, que todas sus fuerças no las enplea syno en retraer a mí por fuerça de lo uno y atraerme a lo ál con tanto que

34 Precisamente el desarrollo de ese género de escritura espiritual, basado en una sólida armazón teológica y en un firme cimiento doctrinal, y facturado según las formas y modos de la retórica al uso en esa tipología textual, hubo de estar en la base de las reacciones de incredulidad, cuando no de indignación, suscitadas por la circulación de Arboleda de los enfermos, y a las que responde la segunda obra de Teresa de Cartagena, Admiración Operum Dei. Esa es, al menos, la hipótesis que subyace a Conde (2015). 
aunque me pese he de querer lo que ella quiere y ella sienpre desquiere lo que yo quiero? Ca sy quiero oýr no me lo consyente; e sy fablare, vame a la mano e claramente me dize no ser otra su yntinçión sinon deve[dar] lo que quiero y hazerme querer lo que no quiero: lo que quiero es enbolverme en las ocupaçiones mundanas, e lo que no quiero es la soledat o apartamiento de todo ello. Pues bien mirada su yntinçión, mejor es que no la mía, ca ella me quiere salvar e yo me quiero perder, ella me quiere arredrar de peligros e yo me quiero lançar en ellos: mucho mejor es la yntinçión de mi pasyón que no la mía. Ya voy conosçiendo su buena voluntat, ca non la ha tanto por me penar como por me salvar, ni tanto trabaja por me hazer padesçer como por me hazer meresçer; e sy me haze sentir grande afliçión, con deseo de mi salvaçión lo haze. Por ende yo loo mucho su buen deseo y denuesto mi rebeldía, digna de todo denuesto, porque tanto tienpo he pugnado contra su piadosa porfía; tienpo es ya que la dexe obrar enteramente aquel fin virtuoso lleno de provecho espiritual por que el Señor me la dio. iO cabestro y freno de pasyón saludable! Sy [h]asta [a]quí me llevavas rastrando y mal paresciendo, en pos de ti agora de mi buen grado te quiero seguir. E pues me sygues, y allí quiero colocar mi morada donde claramente me guías, ¿quánto es a mí provechoso ser atada con estas pasiones, las quales [ca]usan que mi yndomable porfía sea vençida de la misericordia divinal? Pues con cabestro y freno son costreñidas las mexillas de mis vanos deseos porque a Dios non me quería allegar (fols. 10r-10v / pp. 50-51).

Creo no disparatar si digo que muy pocas páginas de las letras hispanas del siglo XV ofrecen una expresión genuina de sentimientos y pensamientos personales de quien escribe tan verdadera como la que aquí presenciamos. Las obras de nuestra autora nos abren con frecuencia - más en Arboleda acaso que en Admiración, escrito más a la contra - su intimidad subjetiva con una desnudez que cabría considerar moderna. Así lo advirtieron ya hace muchos decenios dos estudiosos españoles unidos por vínculos comunes como los del exilio compartido, la ubicación en Norteamérica y, más importante para nuestro propósito, el magisterio de uno sobre el otro. Me refiero a Américo Castro, quien en su España en su historia resaltó este aspecto de las obras de nuestra autora, que asoció a una posible expresividad conversa cuando su condición de tal distaba de estar probada documentalmente, ${ }^{35}$ y a su discípulo Juan Marichal, quien en su memorable La voluntad de estilo situó a Teresa de Cartagena en los estadios iniciales del desarrollo de una sensibilidad expresiva asociable a la presentación textual de ideas y pensamientos pasados por el tamiz de la subjetividad

35 «Aunque casi un siglo antes de Santa Teresa, escribía la monja doña Teresa de Cartagena su Arboleda de los enfermos (hacia 1470) [...]. Cuando hace muchos años me fijé en este pasaje [en referencia al que cita de "Arboleda", que no reproduzco aqui] juzgué que valía como anticipo de "modernidad" psicológica; hoy lo veo como un brote del tronco hispano-islámico, muy antiguo y a la vez muy moderno. Me convendría mucho que doña Teresa de Cartagena descendiese de don Pablo de Santa María, es decir de un judío converso. Algunos lo piensan, pero carezco de argumentos para aceptarlo o rechazarlo. Lo cierto es que maravilla encontrar en el siglo XV una confesión íntima, con conciencia y análisis del yo más íntimo, de "mi yo". De aquí a Santa Teresa no hay sino un paso" (Castro 1948, 324-325n). Pocos años después de la publicación de estas líneas de Castro, Francisco Cantera Burgos probaría documentalmente la pertenencia de Teresa de Cartagena a la familia Santa María-Cartagena (Cantera Burgos 1952, 440-441 y $537-538)$ de quien escribe propia y definitoria de la escritura ensayística (Marichal 1971, 43). Pero esto nos saca de las sendas por las que estas páginas de hoy deben transitar: el cabestro y el freno de la autodisciplina me harán regresar a los cauces del asunto que hoy nos ocupa.

\section{CierRe}

Parece conveniente terminar estas páginas con algunas reflexiones atingentes al significado que cabe extraer del conocimiento del texto bíblico, y del ejercicio de ciertas prácticas culturales relativas al mismo, que se revelan en la escritura de Teresa de Cartagena. Pues la prominencia que las Escrituras, en particular los Salmos, pero también los Evangelios, tienen en el ámbito de las corrientes de espiritualidad renovada de fines de la Edad Media en Castilla, y en especial en lo tocante a la espiritualidad femenina en esos tiempos, tierras y círculos, es indudablemente extraordinaria.

No en vano muchos de los grandes nombres del alumbradismo e iluminismo españoles son nombres de mujer, como es el caso de María de Cazalla, Isabel de la Cruz y Francisca Hernández; es frecuente encontrar conventos femeninos en el centro del desarrollo de ciertas tendencias espirituales y místicas; ${ }^{36}$ no es insólito poder documentar la celebración de lecturas en grupo de las Escrituras en conventículos con significativa presencia femenina. ${ }^{37}$ Los casos individuales, pero sumamente significativos, que documentan la existencia de mujeres con claros intereses espirituales, y, más precisamente, su interés por una nueva espiritualidad, son abundantes. La madre del poeta Garcilaso de la Vega - por poner un ejemplo con vínculos familiares con nuestra autora, vía su madre, Juana de Mendoza, mujer de Gómez Manrique- poseyó una llamativa colección de libros en la que no faltaban algunos títulos indicativos de una inquietud

36 Sobre la presencia sobresaliente de mujeres en el movimiento iluminista o alumbrado, vid. las siempre ricas páginas del Erasmo y España batailloniano (Bataillon 1983, 68-69 y 176-179); para la importancia de algunos conventos femeninos como terreno abonado para «una viva exaltación mística», vid. ibíd., 69.

37 En algunos casos, sabemos de este tipo de prácticas gracias a testimonios que las censuran y condenan. Así, Asensio, en su memorable artículo sobre «El erasmismo y otras corrientes espirituales afines», de 1952 - que cito aquí por su edición en libro (Asensio 2000, 46-47) allega uno presente en el Tratado Ilamado "Excelencias de la Fe", ayuntado de muchas flores de los libros de los excelentes varones assí santos como paganos, colegido por vn religioso de la orden de los menores de la provincia de Santiago. Su anónimo y franciscano autor truena contra las mujercillas que se embarcan en la lectura de las Escrituras: «Si los maestros de las tales personas ouieran mirado $T$ leydo la razon ya dicha de san Augustin no ouiera auido tantas plantas de errores en estos reynos de alumbrados $\tau$ dexados $\tau$ de beatos los quales segun dizen nascieron de leer las epistolas de sant Pablo y no alcançar la alteza dellas. Porque esta es verdad aueriguada entre sabios $T$ personas espirituales: que toda la teologia especulatiua y moral esta escripta por zifras en las epistolas de sant Pablo. Y el sentido literal dellas quanto mas el espiritual es muy dificultoso a los sabios: quanto mas a la señora beata $T$ a la mugercilla que se oluida de la rueca por presumir de leer en sant Pablo. Angeles santos ved tal tempestad: que tiene que ver mugercilla por mas santa que sea con las epistolas de sant Pablo y que tiene que entender religioso ni clerigo en tener escuela con mugercillas de liciones de sant Pablo sino para hacerse dioses $T$ diosas recientes a costa de dios y de la verdad de sant Pablo?» (fols. I. r-v; uso el ejemplar de la Biblioteca Nacional de Austria, signatura 9.W.33.(2)). Tan feroz condena solo tiene sentido si la práctica censurada era frecuente. 
(y un aggiornamento) espiritual más que notable. ${ }^{38}$ Su caso no fue, ni mucho menos, excepcional. Los estudios de Pedro M. Cátedra y Anastasio Rojo han puesto de relieve la presencia eminente de textos bíblicos (más Evangelios y Salterios romanceados, menos Biblias enteras), tratados espirituales, libros de horas y otros textos religiosos en bibliotecas femeninas del XV y del XVI, por lo que lo más prudente es no decir más al respecto aquí. ${ }^{39}$ En algunos casos hallamos mujeres que, como nuestra Teresa de Cartagena, iban más allá de la lectura y la discusión de la Biblia y de obras espirituales, y se adentraban en el territorio de la escritura: la joven Duquesa del Infantado, verosímilmente María Maldonado, segunda esposa del tercer Duque del Infantado, Diego Hurtado de Mendoza de la Vega y Luna - de nuevo, la conexión mendocina-, escribió, con anterioridad a 1530, y en colaboración con el Obispo fray Juan de Cazalla, quien lo vertió al latín, un libro sobre los Evangelios. ${ }^{40}$

Este caso individual vuelve a llevar nuestra atención a un aspecto al que ya nos hemos venido refiriendo a lo largo de estas líneas: la presencia central y fundante de la lectura (y comentario) de las Escrituras en todas estas corrientes de renovación espiritual tardomedievales y de los inicios de la Modernidad. La Biblia en general, pero de manera particular los Evangelios y los Salmos, aparecen de manera prominente en la totalidad de corrientes e impulsos de renovación espiritual. No es necesario irse lejos para ver ejemplos vinculados a Teresa: luminarias de la espiritualidad conversa como Alonso de Cartagena se acogen con laboriosa firmeza al mensaje evangélico para formular sus argumentaciones teológicas en obras como el Defensorium Unitatis Christianae (y recordemos la condición de eximio biblista de don Pablo de Santa María, padre de Alonso de Cartagena y abuelo de nuestra autora); obras como los Evangelios y Epístolas con sus exposiciones en romance de Gonzalo García de Santa María (pese a su apellido, no relacionado con la familia de nuestra autora, pero ciertamente converso también), o las Epístolas y Evangelios por todo el año de Fray Ambrosio Montesino (o por él actualizadas), que constituyen apreciables éxitos editoriales en la imprenta incunable y en los primeros años de la imprenta

38 Vid. Asensio (2000, 80-81). El inventario, efectuado entre diciembre de 1537 y enero de 1538, contiene La historia de San Francisco e Santa Clara y un Enchiridion del caballero cristiano, obviamente el romanceamiento de Alonso Fernández de Madrid, que son los títulos destacados por Asensio; pero además contiene una Vita Christi, una Uida de Nuestro Señor Jesuchristo, una Espusicion de los Euangelios dominicales, el Carro de dos uidas, un «Libro pequeño de como an de biuir las rreligiosas de San Bernardo» (que parece fundado identificar con la Suma y breve compilación de cómo han de bivir y conversar las religiosas de Sant Bernardo que biven en los monasterios de la cibdad de Ávila de fray Hernando de Talavera, un Espexo de la Pasión de Jesuchristo, entre otros, y amén de dos ejemplares de las inevitables Horas de Nuestra Señora, ambos manuscritos, uno de ellos en pergamino (Escritura de inventario, tasación y partición de los bienes que quedaron por fin y muerte de doña Sancha de Guzmán, mujer de don Garcilaso de la Vega, en Laurencín (1915, 115-153 para el documento completo —editado a través de un traslado de 1677-; pp. 133-134 para la sección que se ocupa de los que fueron sus libros). Un elenco que muestra las inquietudes espirituales de una mujer de la nobleza española de comienzos del XVI.

39 Cátedra y Rojo (2004) - especialmente interesante para nuestros propósitos aquí su capítulo IV) - y Cátedra (1999 y 2005, 31-126); especialmente el primer capítulo de la primera parte («Vida, lectura y transfondo intelectual»).

40 Vid. para esto Bataillon (1983, 211-212). quinientista, ilustran claramente ese interés por ciertos textos bíblicos en la época. Conviene también señalar aquí otra conexión con la familia Mendoza: Íñigo López de Mendoza, el Marqués de Santillana por antonomasia, encomendó a Martín de Lucena, apodado el Macabeo, una versión castellana del Nuevo Testamento y de las epístolas paulinas en la década de los treinta del siglo XV. Esta traducción, hoy solo conservada en parte, debió ser, conjetura Stefania Pastore (creo que con acierto), la que manejó Diego Hurtado de Mendoza, primer Duque del Infantado, quien «estudió la Sagrada Escritura, leyendo los padres, los expositores y glosas». ${ }^{41}$

Son tendencias profundas y duraderas, que presiden los itinerarios de renovación espiritual del XV y el XVI. Lo atestigua, y con referencia específica al Salterio, que nos interesa especialmente ahora, fray Domingo de Valtanás, cuando dejó escrito:

Y assí el psalterio de David devrían todos los Christianos traer en las manos como a breviario de toda la divina ley y como a devocionario donde están recogidas todas las devociones que el Christiano deve tener [...]. Y como mandan los prelados poner en las yglesias el libro de los evangelios en romance, ansí devrían proveer que uviesse esse psalterio en romance, pues es la letura que de día y de noche, en fiestas y en ferias y en todo tiempo, a todas horas más se tracta en los divinos officios. ${ }^{42}$

Es particularmente interesante el pasaje por lo que tiene de recomendación de la lectura frecuente y continuada del Salterio a los fieles, por mostrar el carácter de compendio devocional comprehensivo y, colateralmente, por mostrar la presencia y circulación de los Evangelios romanceados en la iglesia peninsular del XVI. Este perfil y esta visibilidad específicos de las escrituras en el XVI es tanto más importante si consideramos que describe, prácticamente al centímetro, los del saber escriturístico característico de los alumbrados, tal y como lo define Antonio Márquez en su memorable estudio. ${ }^{43}$ Esto da pie para añadir un rasgo más de la

41 Pastore (2010, 60). Pastore ofrece un sucinto panorama-resumen de la presencia del biblismo en el XV-XVI (2010, 58-61).

42 Fray Domingo de Valtanás, "La vida y hechos del propheta David», en su Apología del maestro fray Domingo de Valtanás sobre materias en que hay opinión (Sevilla, 1557), fols. 44-45; cito a partir de Asensio, (2000,44-45). En esas páginas recoge también (45) la noticia de que en el Concilio de Trento el Cardenal Pacheco, pese a su rechazo a verter las Escrituras al vulgar, transigía a ello en el caso de los Salmos, los Proverbios y los Hechos de los Apóstoles, libros bíblicos considerados de especial valor o mérito, que parece sumamente reveladora de un esprit du temps no lejano, o no muy divergente, de aquel en que Teresa de Cartagena vivió y escribió. Dicha noticia va acompañada de la mención de la existencia de unos Proverbios de Salomón interpretados en metro español impresos en Cuenca, 1558 (ejemplar en la Hispanic Society de Nueva York).

43 «Los maestros del iluminismo no conocían más textos de la Sagrada Escritura que los del ciclo litúrgico. Probablemente Los Evangelios y epístolas con sus exposiciones en en romance según la versión de Gonzalo de Santa María [...]. O el Vita cristi cartuxano romançado por fray Ambrosio Montesino. O cualquiera otro Salterio o Libro de horas de los que circulaban por Castilla la Nueva "impresos o a mano" y que eran propiedad común del pueblo antes que se decretasen las drásticas medidas provocadas por la Reforma. De cualquier manera que sea, las citas bíblicas atribuidas a los alumbrados no rebasan los límites del Nuevo Testamento, excepto en dos citas de los salmos atribuidas a Alcaraz. [...] Los maestros alumbrados se mueven dentro del mismo círculo reducido de textos bíblicos que los demás fieles castellanos de la época» (Márquez, 1980, 113). 
espiritualidad alumbrada (el término doctrina resulta particularmente inadecuado en su caso) advertido por algunos estudiosos: la idea de que nadie debe actuar como intermediario entre el buen cristiano y la palabra de Dios en lengua vulgar. No ya los frailes o los teólogos a que Erasmo profesaba inquina (y a los que se alude en el próximo párrafo), sino ni tan siquiera la propia persona de Cristo (Márquez 1980, 114).

Cuando hablamos de biblismo, de accesibilidad al texto bíblico, de filología bíblica y hasta de las Escrituras en vulgar en la temprana Modernidad europea, el nombre de Erasmo viene inmediatamente a la mente. No tiene sentido intentar aquí recapitular la importancia de su figura o enumerar sus logros al respecto - o los de algunos de sus más conspicuos seguidores hispánicos, como Juan de Valdés. Pero sí me interesa comentar que en algunas ocasiones Erasmo dirigió sus alegatos en pro de la lectura directa de la Biblia, sin mediación de teólogos o intérpretes, de manera específica a las mujeres. Como dice Bataillon, glosando la erasmiana Paraclesis ad philosophiae Christianae studium (1516):

La verdad más excelsa ha sido traída por Cristo bajo forma muy diversa. Si es cierto que los cristianos son discípulos suyos, lo único que tienen que hacer es acudir a su palabra: ésta puede prescindir muy bien de los comentarios y especulaciones que la oscurecen so pretexto de iluminarla. Es como un alimento tan simple que todos lo pueden tomar. Para saborearlo, basta tener el corazón puro y lleno de fe [...]. Así, la tarea urgente entre todas es la de hacer resonar la palabra de Dios. Cualquier mujer debería leer los evangelios y las epístolas, y estos libros deberían traducirse a todas las lenguas de la tierra. Sus palabras deberían ser las canciones preferidas del labrador que va a los campos, del tejedor sentado en su taller, de los viajeros en los caminos. Los enemigos jurados de esta vulgarización ilimitada del Evangelio son los teólogos profesionales y los frailes, que se arrogan una especie de monopolio del cristianismo puro. Pero el teólogo digno de este nombre bien puede ser un tejedor o un jornalero: [...] la filosofía de Cristo debe ser vivida, no argumentada (Bataillon 1983, 75, cursiva mía).

Como es bien sabido, esta aspiración a la lectura inmediata del mensaje bíblico y su aplicación libre a una vida evangélica, al margen de la Iglesia, será la que dispare un sin fin de alarmas cuando grupos que alzan esa bandera comiencen a ser percibidos como heterodoxos o, directamente, como heréticos. El texto bíblico dirá cosas distintas a distintos lectores y receptores, y esa dispersión, con inclinaciones heterodoxas, será la que en último término suscite la necesidad de una acción correctiva decidida e irrevocable. La Inquisición y el concilio de Trento se cuidarán de ello, cerrando un camino de renovación espiritual con base en la lectura meditativa de las Escrituras a cuyos inicios es lícito asociar a Teresa de Cartagena.

\section{BibLIOgRAFÍA}

Asensio, Eugenio. 2000. El erasmismo y las corrientes espirituales afines. Conversos, franciscanos, italianizantes. Con algunas adiciones y notas del autor. Salamanca: SEMYR.

Bataillon, Marcel. 1983. Erasmo y España. Estudios sobre la vida espiritual del siglo XVI. México: Fondo de Cultura Económica.
Biblia, c 1487. Biblia Sacra cum Postilla Litteralis Nicolai Lyrani et Additionis ad Postillae Nicolae Lyranis Pauli Sanctae Mariae Episcopus Burgensis. [Nuremberg]: s.i.t.

Cantera Burgos, Francisco. 1952. Álvar García de Santa María y su familia de conversos. Madrid: CSIC.

Cartagena, Teresa de. 1967. Arboleda de los enfermos. Admiraçión Operum Dey, ed. Lewis J. Hutton. Madrid: Real Academia Española.

Cartagena, Teresa de. En prensa. Arboleda de los enfermos. Admiración Operum Dei, ed. Juan-Carlos Conde. Madrid: Cátedra.

Castro, Américo. 1948. España en su historia (judíos, moros y cristianos). Buenos Aires: Editorial Losada.

Cátedra, Pedro Manuel. 1999. «Lectura femenina en el claustro (España, siglos XIV-XVI)». En Des femmes et des livres. France et Espagne, XIVe-XVIle siècle, ed. Dominique De Courcelles y Carmen Val Julián, 7-53. París: École des Chartes.

Cátedra, Pedro Manuel. 2005. Liturgia, poesía y teatro en la Edad Media. Madrid: Editorial Gredos.

Cátedra, Pedro Manuel y Anastasio Rojo. 2004. Bibliotecas y lecturas de mujeres (Siglo XVI). Madrid: Instituto de Historia del Libro y la Lectura.

Conde, Juan-Carlos. 2015. "Malos saberes en según que manos: escritura, autoridad y género en Teresa de Cartagena». En Los malos saberes. Actas del Coloquio Internacional de Tréveris (noviembre del 2013), ed. Folke Gernert, 45-62. Toulouse: Presses Universitaires du Midi, Université Toulouse - Jean Jaurès.

Conde, Juan-Carlos. En prensa. "Self-fashioning and the intersectional self: Teresa de Cartagena by Teresa de Cartagena». En Claiming Authority in Spanish Women's Writing, ed. María Morrás.

Infantes, Victor. 2001. "Tipologías de la enunciación literaria en la prosa áurea. Seis títulos (y algunos más) en busca de un género: libro, obra, tratado, crónica, historia, cuento, etc. (V)». En Actas del $\checkmark$ Congreso de la AISO (Münster 1999), ed. Christoph Strosetzki, 730-736. Madrid - Frankfurt: Iberoamericana - Vervuert.

Laurencín, Marqués de. 1915. Documentos inéditos referentes al poeta Garcilaso de la Vega. Madrid: Establecimiento tipográfico de Fortanet.

Marichal, Juan. 1971. La voluntad de estilo. Teoría e historia del ensayismo hispánico. Madrid: Revista de Occidente.

Márquez, Antonio. 1980. Los alumbrados. Orígenes y filosofía (15251559). Madrid: Editorial Taurus.

Pastore, Stefania. 2010. Una herejía española. Conversos, alumbrados e Inquisición (1449-1559). Madrid: Marcial Pons.

Pearson, Hilary E. 2010. Teresa de Cartagena: A late medieval woman's theological approach to disability. Tesis doctoral. University of Oxford.

Rendtorff, Rolf. 2005. "The Psalms of David: David in the Psalms». En The book of Psalms. Composition and Reception, ed. Patrick D. Miller y Peter W. Flint, 53-64. Leiden: Brill.

Seidenspinner-Núñez, Dayle y Yonsoo Kim. 2004. «Historicizing Teresa: Reflections on New Documents Regarding Sor Teresa de Cartagena». La Corónica 32 (2): 121-150. https://doi.org/10.1353/ cor.2004.0000

Serrano, Luciano. 1942. Los conversos D. Pablo de Santa María y D. Alfonso de Cartagena: obispos de Burgos, gobernantes, diplomáticos y escritores. Madrid: Instituto Arias Montano, CSIC.

Toro Pascua, Isabel. 2008a. «I. Edad Media. I.1. El imaginario y sus géneros». En La Biblia en la literatura española, coord. Gregorio del Olmo Lete. Madrid: Editorial Trotta.

Toro Pascua, Isabel. 2008b. «I. Edad Media. I.2. El texto: fuente y autoridad». En La Biblia en la literatura española, coord. Gregorio del Olmo Lete. Madrid: Editorial Trotta.

Whinnom, Keith. 1982. "Autor and tratado in the fifteenth century: semantic latinism or etymological trap?». Bulletin of Hispanic Studies 59: 211-218. https://doi.org/10.3828/bhs.59.3.211 